\title{
Calidad estética del entorno escolar: el (f)actor invisible
}

\section{Aesthetic quality of the school environment: The invisible (f)actor}

\author{
LUIS H. ERRÁZURIZ-LARRAÍN \\ Instituto de Estética, Universidad Católica de Chile. \\ lerrazur@puc.cl
}

Recibido: 14 de enero de 2014

Aprobado: 29 de abril de 2014

\section{Resumen}

Este artículo se propone abordar la estética cotidiana del entorno escolar como un factor que podría contribuir al mejoramiento de la calidad de la educación, y proponer una reflexión acerca del modo como concebimos las reformas educativas, más allá de la definición de estándares y la medición del rendimiento en asignaturas o materias tales como matemáticas y lenguaje. No hay investigación en Chile, ni estudios o publicaciones sistemáticas en relación con la dimensión estética de los espacios de aprendizaje escolar. Consecuentemente, existe la necesidad de abordar el tema, considerando perspectivas históricas y contemporáneas, para comprender mejor la situación actual y desde aquí aportar a la construcción de ambientes educativos más interesantes y sustentables.

Con este propósito, primeramente, se consideran algunos planteamientos desde una perspectiva histórica y contemporánea sobre las dimensiones materiales y estéticas del entorno escolar para ilustrar cómo estas pueden afectar la calidad de la educación; en segundo lugar, surge la necesidad de fundamentar la importancia de la experiencia estética cotidiana, considerando el pensamiento de prominentes investigadores en este campo. Por último, se proponen algunos temas y preguntas claves para reflexionar sobre la calidad estética del entorno escolar.

Palabras clave: calidad estética, entorno escolar cotidiano.

Errázuriz-Larraín, L.H. (2015): Calidad estética del entorno escolar: el (f)actor invisible. Arte, Individuo y Sociedad, 27(1) 81-100

\begin{abstract}
The purpose of this article is to consider everyday aesthetics of the school environment as a factor which could contribute to improve the quality of education and the way we understand school reforms, beyond the definition of standards and the measurement of performance in subjects such as math and language. There is no research and systematic studies about the aesthetic dimension of schools' learning spaces in Chile. Consequently, there is a need to approach this issue to better understand the present state of affairs and hence create more interesting and sustainable environment in our schools.

Firstly, some historical and contemporary arguments regarding the material and aesthetic dimensions of the school environment are considered in order to illustrate how they may affect the quality of education, and then, the need to support the importance of everyday aesthetic experiences emerge by considering the thought of prominent researchers in the field. Finally, some key issues and questions related to the aesthetic quality of the school environment are proposed to reflect about.
\end{abstract}

Keywords: aesthetic quality, everyday school environment. 
Sumario: 1. Introduction, 2. El imperativo de la calidad, 3. Condiciones materiales y estéticas del entorno escolar, 4. Aproximaciones emergentes para crear nuevos espacios de aprendizaje, 5. La necesidad de prestar atención a la estética cotidiana del entorno escolar, 6. Conclusiones. Referencias.

\section{Introducción}

La necesidad de mejorar la calidad estética del entorno escolar -sus condiciones materiales, espaciales, visuales, sonoras y olfativas- debería ser una prioridad de las reformas educacionales, no solamente para contribuir a generar una atmósfera más adecuada que favorezca los procesos de enseñanza y aprendizaje, sino también para enriquecer el sentido mismo de la educación más allá de sus propósitos académicos. En efecto, mantener y conservar la infraestructura destinada a la enseñanza, optimizar la distribución e iluminación de los espacios educativos, cuidar la selección de colores, la elección de imágenes desplegadas en los muros, el tipo de mobiliario, los materiales didácticos, los objetos que rodean el ambiente, las áreas verdes, la higiene y la dimensión sonora, entre otros aspectos, son acciones que podrían contribuir al desarrollo cultural y el bienestar social del país. Dicho en otras palabras, si los espacios educativos fueran estéticamente más dignos e interesantes, la experiencia cotidiana de millones de estudiantes -que deben permanecer extensas jornadas escolares en los establecimientos- tendría mayor sentido y brindaría más oportunidades para el desarrollo de la sensibilidad y de diversos modos de cognición (véase Errázuriz 2006).

En Chile -como en otros países de la región- la infraestructura escolar y las condiciones ambientales de no pocos establecimientos educacionales son precarias, situación que se manifiesta en distintos contextos culturales, zonas geográficas y que refleja la desigualdad en la que deben formarse muchos estudiantes. Como concluyen Duarte Duarte, Gargiulo y Moreno en su investigación Infraestructura Escolar y Aprendizajes en la Educación Básica Latinoamericana (2011):

Los resultados del estudio evidencian que "las condiciones de infraestructura educativa y el acceso a los servicios básicos (electricidad, agua, alcantarillado y teléfono) de las escuelas de la región son altamente deficientes; existe gran disparidad entre países $y$ entre escuelas privadas urbanas, públicas urbanas y públicas rurales; $y$ hay grandes brechas en la infraestructura de escuelas que atienden a los niños de familias de altos y bajos ingresos (p.1).

Pero no se trata sólo de una pobreza material o de la carencia de una infraestructura adecuada para la enseñanza, también existe un descuido de los "valores sensibles del entorno" (Porcher, 1975). Esta falta de atención y/o invisibilidad de la dimensión estética se puede constatar en diversas realidades escolares, según los antecedentes que arroja la investigación "La Estética Cotidiana en Establecimientos Escolares de la Comuna de Peñalolén: Cultura Visual de los Muros". ${ }^{1}$

A modo de ejemplo, en la fotos 1 y 2 presentamos imágenes de una escuela municipal de dicha comuna frente a las cuales podemos formular -entre otras- las siguientes preguntas: ¿Qué percibimos?, ¿Qué sensaciones estéticas nos provocan?, ¿Qué revelan de la institución escolar?, ¿Qué "enseñan" implícitamente a los estudiantes? Sin pretender abordar estas interrogantes, algunas respuestas tentativas 
podrían aludir a sentimientos de precariedad, recuerdos de un mausoleo, desolación y frialdad, lo que podríamos denominar una "estética del abandono".

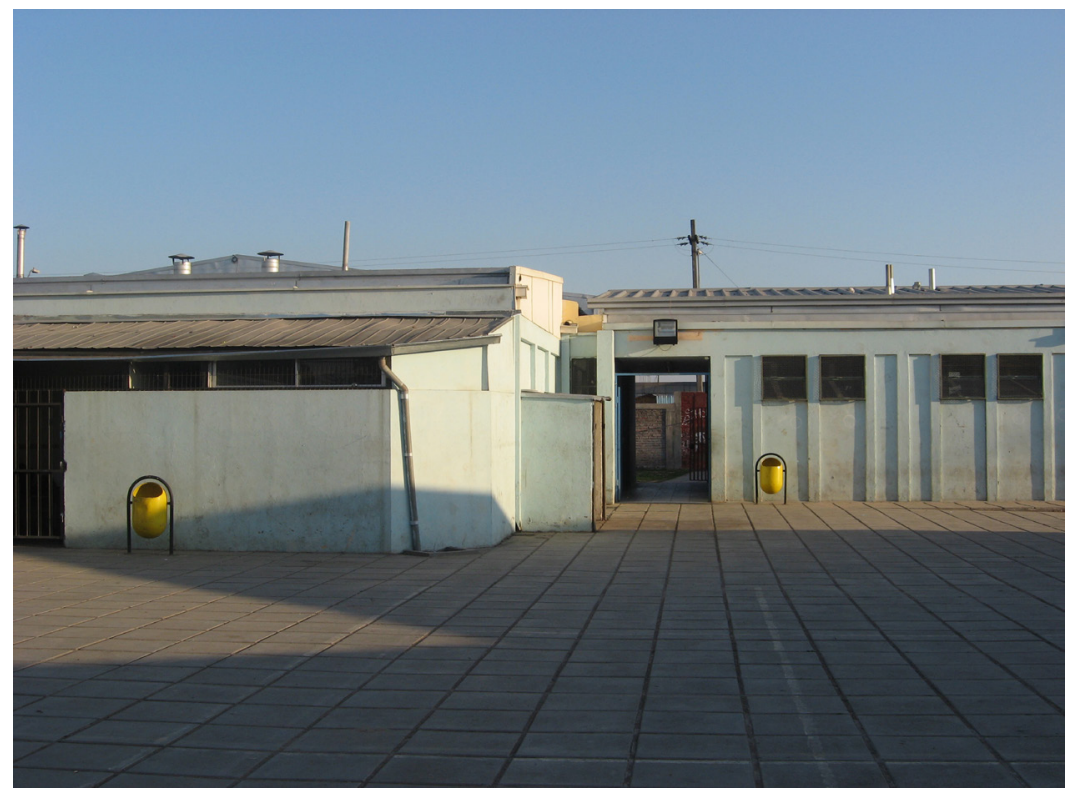

Figura 1.

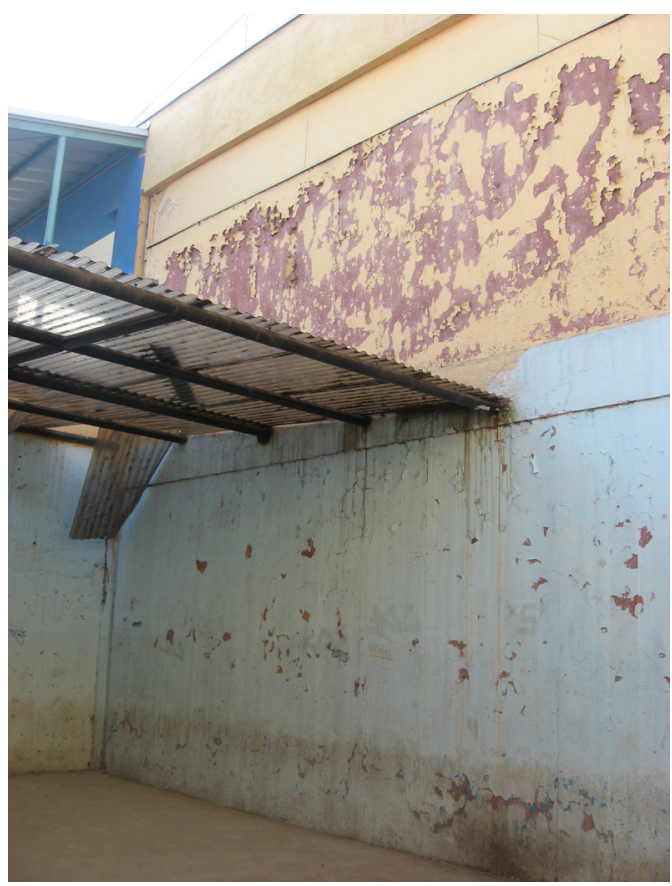

Figura 2. 
Las mismas preguntas pueden formularse respecto a la fotos 3 y 4 , correspondientes a un establecimiento escolar privado de la comuna de Peñalolén, en las que podemos observar la presencia de la naturaleza y de murales que evidencian la identidad regional y juvenil. En este caso, el colegio ha defendido una perspectiva estético-visual que guarda coherencia con el proyecto educativo que ahí se desarrolla. En efecto, otorga un protagonismo significativo a la formación artística de sus estudiantes, impulsando en ellos un sentido de creatividad que se advierte refrendado en los numerosos murales que son posibles de observar en patios y pasillos. Estos murales son creación del propio alumnado, y esto resulta ser un hecho elocuente, pues el colegio ofrece los espacios indicados, y claramente delimitados, para materializar el producto de aquellas habilidades que distinguen a este establecimiento respecto de otros ubicados en la misma comuna.

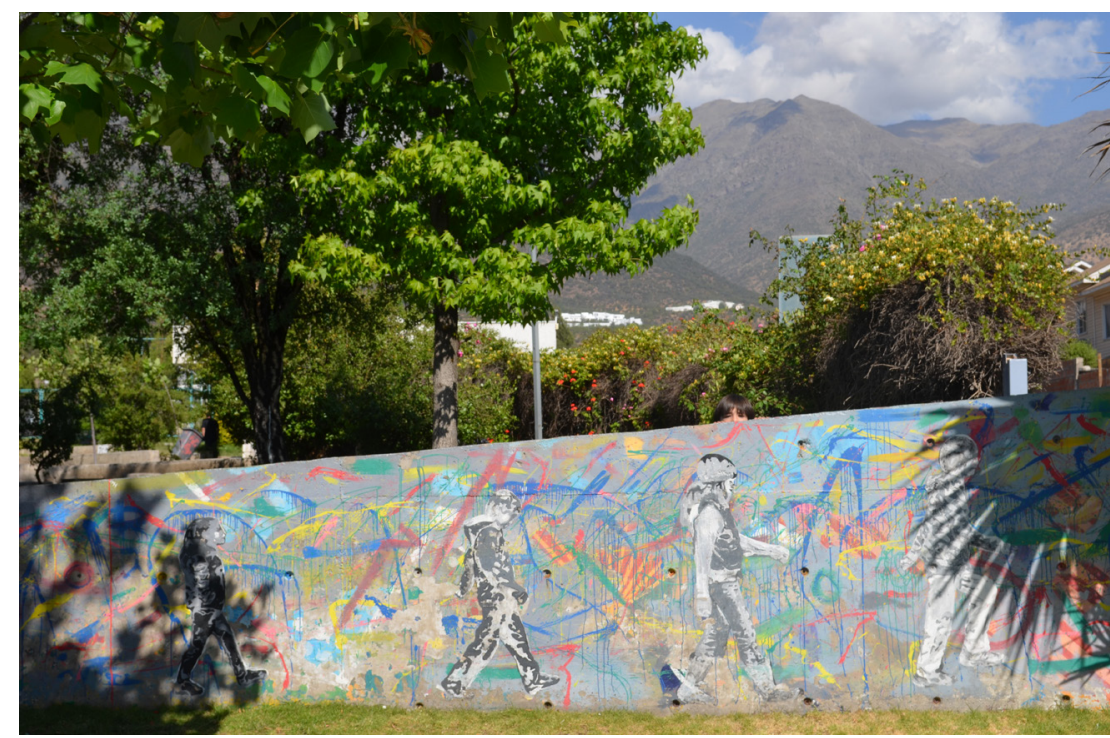

Figura 3.

Algo similar ocurre en la relación que el edificio entabla con su entorno natural. La gran mayoría de las construcciones que integran los recintos del colegio se encuentran hechos con hormigón armado a la vista, es decir, sin monocapa e incluso sin revestimiento de pintura de tipo alguno. Ello no sólo se constituye como un soporte interesante para los mencionados murales, sino también establece conexiones estéticas con la arquitectura contemporánea, con la noción de dejar la materialidad desnuda, a la vista de los usuarios de los edificios, y además de confrontarse a la naturaleza. Peñalolén, al ser una comuna ubicada en los faldeos precordilleranos, es un sitio pródigo en vistas donde el verde, las cumbres andinas, el cielo celeste prístino, y otros elementos excepcionales en el escenario citadino, son abundantes. Deliberadamente consciente de ello, el diseño del edificio y de sus pabellones busca enmarcar y resaltar esas cualidades del entorno, estimulado, nuevamente, la percepción visual de los estudiantes. 


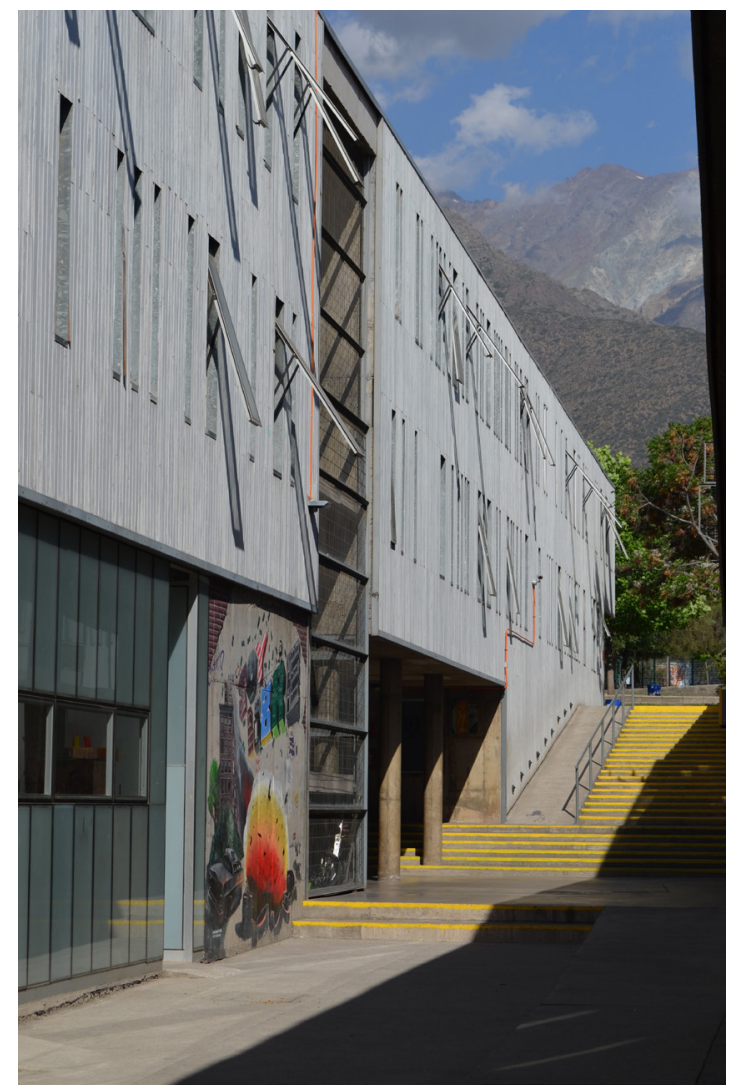

Figura 4.

El contraste que evidencian las fotos de ambos establecimientos -entre otras examinadas- motivó la investigación sobre la calidad estética del entorno escolar cotidiano, algunos de cuyos contenidos se esbozan en el presente artículo, dando cuenta de la complejidad que supone generar espacios educativos estéticamente consistentes.

Porque no basta con maquillar el rostro de la escuela, decorarlo y/o camuflarlo cada cierto tiempo con la intención de hacerlo más atractivo pintando sus muros, remodelando alguno de sus espacios, áreas deportivas o salas de clase. Más allá de esta práctica y/o ritual, que suele marcar el inicio de un nuevo año escolar, se requiere de una "cirugía estética" más consistente, vale decir, reflexionar, discernir e intencionar con mayor lucidez, imaginación y pluralismo cómo los entornos escolares pueden favorecer una educación de calidad y, por ende, contribuir a un mayor desarrollo personal, social y cultural. Al respecto, las investigadoras norteamericanas Deb Curtis y Margie Carter (2003), plantean que debemos preguntarnos qué valores queremos comunicar a través del entorno y qué queremos que los niños experimenten mientras se encuentran en el establecimiento educacional. No se trata de un problema relacionado con la decoración, sino de reflexionar cuidadosamente sobre nuestras 
creencias acerca de los niños, los adultos y el aprendizaje, a fin de desarrollar espacios y materiales que comuniquen un profundo respeto por los estudiantes, sus familias y el proceso de enseñanza.

Frente a este impostergable desafío, resulta preocupante -por no decir inaceptableque el tema de la calidad de la educación se relacione, casi exclusivamente, con el rendimiento obtenido en las asignaturas evaluadas en los rankings nacionales e internacionales, principalmente en las áreas de lenguaje y matemáticas, cuyo objetivo central es medir logros y deficiencias académicas.

Pero no solo la educación tiende a ser concebida con un enfoque limitado. La estética, suele ser restringida a una rama de la filosofía cuyo objeto privilegiado de estudio son las artes, o bien al mundo de la moda, los salones de belleza, etc., desconociéndose la importancia que la experiencia de la sensibilidad puede tener como un factor determinante en la configuración de la vida cotidiana, sus instituciones, escenarios y prácticas. Es precisamente desde esa perspectiva -reconociendo la dimensión estética de la educación y el potencial educativo de la sensibilidad- que proponemos abordar el tema de la calidad estética del entorno escolar.

Con este propósito, primeramente se plantean algunas consideraciones sobre el concepto de calidad en la educación; luego se esbozan antecedentes históricos relativos a las condiciones materiales y estéticas del entorno escolar. A partir de estos planteamientos, se aborda el pensamiento de autores contemporáneos que advierten la necesidad, por una parte, de investigar la relación entre calidad del ambiente y aprendizaje escolar y, por otra, de visibilizar la estética cotidiana como un factor que puede repercutir seriamente en múltiples ámbitos de la experiencia social y personal; en lo educativo, político, ético, entre otros. Por último, se formula un listado de preguntas que se desprenden del marco teórico y tienen por objeto contribuir a la reflexión sobre el tema.

\section{El imperativo de la calidad}

Mejorar la calidad de la educación es, sin duda, una de las prioridades más urgentes de la agenda pública chilena y de muchos países a nivel internacional ${ }^{2}$. Iniciativas gubernamentales y privadas, debates académicos, publicaciones, un aumento en la cobertura de prensa y en la asignación de recursos así lo evidencian ${ }^{3}$. Obviamente, las opiniones sobre cómo enfrentar el tema y los enfoques de estudio son diversos ${ }^{4}$. Sin embargo, más allá de estas legítimas diferencias, existe consenso en que la educación debe jugar un rol fundamental para impulsar el desarrollo. A modo de ejemplo, un grupo de académicos afirma: "La educación es el instrumento más poderoso de que disponen las personas, familias y países para desarrollarse y mejorar sus perspectivas. La educación es, en efecto, la base fundamental de las oportunidades que tienen las personas a lo largo de la vida y constituye el sustento básico de la productividad y desarrollo de los países. Estas características hacen que la educación sea al mismo tiempo una tarea primordial de la familia y un deber ineludible del estado"s.

Así, desde una perspectiva instrumental, los debates sobre la calidad de la educación suelen reducirse al desarrollo económico del país, la generación de recursos humanos calificados y, por ende, al logro de una mayor competitividad en los mercados internacionales. Elliot Eisner $^{6}$, analizando críticamente esta perspectiva, plantea 
que el desafío de la calidad no se debe reducir exclusivamente a la medición del rendimiento escolar con un enfoque eminentemente cuantitativo. Es más, considera que las reformas educativas que son concebidas y aplicadas con una racionalidad predominantemente instrumental, desvirtúan el sentido mismo de la educación, transformándola en un accidente, en una mercancía, un producto que genera el país para competir en la economía global. En su opinión, necesitamos una mirada fresca y más humana para imaginar cómo transformar el futuro de la educación, por cuanto lo que lleguen a ser nuestras escuelas definirá en gran medida lo que puedan ser nuestros niños(as) y nuestra cultura (Eisner, 2005).

En consecuencia, no basta con aumentar la eficiencia y la medición del rendimiento escolar -por necesarios y relevantes que éstos puedan ser- para garantizar una buena educación. El concepto de calidad es complejo y multidimensional; se puede hablar, por ejemplo, de calidad del docente, de los aprendizajes, de los procesos educativos y de la infraestructura (Arredondo, 2007). De este modo, el mejoramiento de la calidad de la educación no sólo implica subir los puntajes en las áreas de matemáticas y lenguaje -asignaturas medidas por el $\mathrm{SIMCE}^{7}$ y/o la $\mathrm{PSU}^{8}$ - como se plantea en el siguiente titular publicado por un medio de comunicación:

"Simce 2010: se confirma mala calidad de educación chilena...

La mala educación: $62 \%$ de los alumnos de octavo básico van dos años atrasados en Matemáticas"'.

No obstante, si la educación fuera concebida desde una perspectiva más humana e imaginativa, como propone Eisner, las temáticas y los indicadores asociados a la calidad cubrirían un espectro más amplio de intereses y preocupaciones que, a modo de ejemplo, podría reflejarse en los siguientes titulares de prensa imaginarios:

Simce 2016: se confirma mala calidad de educación chilena... 77\% del alumnado de primer ciclo básico confunde a grandes músicos, pintores y poetas chilenos -Claudio Arrau, Roberto Matta y Pablo Neruda-con personajes del mundo de la farándula y del deporte.

$(O E C D)^{10}$ 2017: Nuevos espacios educativos para mejorar calidad de la enseñanza. Investigaciones recientes han demostrado que la construcción de ambientes educativos que consideren seriamente la dimensión estética y valoren la identidad local, contribuyen a estimular el proceso de enseñanza y aprendizaje de los estudiantes y su potencial creativo. No obstante, según los resultados de la última encuesta Edumark, más del 50\% de los establecimientos educacionales en Chile todavía son clasificados en la categoría "escuelas /cárceles.

Necesitamos una educación que evidencie de un modo más consistente su vocación cultural, que sea estéticamente más interesante, pero a la vez más lúcida y eficiente en su compromiso ético - social, contribuyendo, por ejemplo, a una mayor conciencia medio ambiental y al cuidado de la naturaleza. Si la educación descuida estas dimensiones no podrá ser considerada genuinamente de calidad (Errázuriz, 2006). Desde esta perspectiva, mejorar la calidad de la educación implica -entre otros 
desafíos- crear una atmósfera estético-pedagógica más coherente, que no sólo esté a la altura de los estándares académicos que se quieren lograr, sino que también pueda desarrollar en la comunidad escolar la capacidad de percibir los valores del entorno educativo. Según Louis Porcher (1975), lo que fundamentalmente se halla en juego en la educación estética son los valores del entorno, la calidad de vida. Este objetivo adquiere mayor importancia aún si se considera el aumento de horas de permanencia en las escuelas, como consecuencia de la puesta en marcha de la "Jornada Escolar Completa" que se está implementando progresivamente a nivel nacional.

\section{Condiciones materiales y estéticas del entorno escolar}

La reflexión pedagógica en Chile sobre las condiciones físicas y materiales de la educación primaria se remonta a mediados del siglo XIX. En esa época, la precariedad de numerosos locales era tan grande que los visitadores de las escuelas públicas clamaban a las autoridades para que se cumplieran, al menos, las condiciones mínimas que permitieran llevar a cabo la labor educativa. Estos requerimientos se evidencian, por ejemplo, en el siguiente informe del visitador J. Santos Rojas (1854):

La letanía de casos particulares va puesta en todas las escuelas... i esto mismo llama la atención del gobierno sobre la construcción de nuevos edificios, cómodos por todos respectos, que con propiedad puedan llamarse casas de escuela i no casas de habitación como lo son actualmente i que solo merecen el nombre que les damos por reunirse en ellas alumnos i maestro: unos i otros confusos por no saber adonde volver los ojos para escapar de las incomodidades que les proporciona el desabrigo, la oscuridad, el desaseo $i$ la estrechez de las casas por un lado: la escasez de mesas asientos $i$ de todos los útiles $i$ materiales necesarios en una escuela por otro (Egaña, 2000).

A comienzos del siglo XX, pese a los esfuerzos públicos y privados, las carencias y el deterioro de no pocas escuelas continuaba siendo un problema de gran magnitud. Al respecto, la doctora Eloísa Díaz advierte a las autoridades sobre la imperiosa necesidad de cuidar la higiene y mejorar las condiciones materiales:

"Sin duda que es un sarcasmo predicar las reglas de la higiene y hablar de las excelentes cualidades del buen aire, de la acción bienhechora de la luz y del calor del sol, en edificios que son la negación completa de estos principios fundamentales" (Díaz, 1902).

Como se puede apreciar, en estos primeros informes y/o denuncias sobre la precariedad del entorno escolar, el desafío fundamental de aquella época era satisfacer las necesidades básicas (locales, mobiliario, útiles y textos) para hacer posible la enseñanza. Con el pasar del tiempo, surgirán algunas propuestas relativas a la calidad estética del entorno escolar. Tal es el caso, por ejemplo, del planteamiento hecho por Maximiliano Salas (1913:462), quien sostiene que el desarrollo estético lo da el mismo establecimiento educacional mediante el cuidado de su entorno. Cabe destacar el aporte visionario de este educador quien, hace más de un siglo, advierte la importancia de promover recomendaciones concretas a nivel escolar como, por 
ejemplo: un aseo exigente, presencia de la naturaleza a través de arreglos florales y jardines, la participación de artistas en la decoración de establecimientos con un sentido nacional y regional, iniciativa que será implementada en la década de 1990 en Inglaterra ${ }^{11}$; y más tarde replicada en algunos países como Chile bajo el nombre "Artistas en Residencia".

Podríamos citar otros autores que durante las primeras décadas del siglo veinte han reflexionado sobre las condiciones materiales y estéticas del entorno escolar y sus consecuentes implicancias pedagógicas (por ejemplo, Amanda Labarca). Sin embargo, la preocupación demostrada por este tema en el pasado -en nuestro paíscontrasta con la ausencia de investigación y de propuestas concretas en el presente. En efecto, poco o nada se ha indagado en Chile acerca de la calidad estética de los ambientes educativos actuales, su arquitectura, distribución de espacios, decoración, mobiliario, materiales didácticos, áreas verdes, higiene, sistemas de reciclaje y otros ${ }^{12}$.

Es más, en la Ordenanza General de Urbanismo y Construcción, en lo concerniente a la arquitectura de los establecimientos escolares en Chile (título IV, capítulo V), tampoco se plantean recomendaciones sobre los estándares -mínimos- estético / ambientales que deberían cumplir los futuros espacios educativos. Las únicas referencias que allí aparecen se reducen a las condiciones físicas que deben tener los edificios, definiendo básicamente normas de construcción de las superficies en relación con la cantidad de estudiantes y estableciendo criterios básicos sobre su iluminación y ventilación.

Sin embargo, el diseño de políticas públicas no debiese tener por objeto controlar y/o regular centralizadamente las condiciones estéticas del entorno escolar, de modo que todos los establecimientos cumplan con estándares uniformes en relación al color de los muros, la distribución de los espacios, la decoración de las salas, etc. Sin embargo, es necesario definir algunas normativas y/o recomendaciones, especialmente para la construcción de los nuevos establecimientos de educación pública y privada -y/o su remodelación- de modo que, por ejemplo, un porcentaje del espacio sea destinado a las áreas verdes, que existan sistemas de reciclaje y ahorro de energía y que, en un marco de pluralismo estético, se tenga en cuenta la identidad regional y local a través del diseño arquitectónico, el uso de materiales de la zona, etc. Por cierto, la definición de estas normativas debería ser objeto de un estudio riguroso, en el que participen, entre otros, un equipo multidisciplinario capaz de cautelar la pertinencia, relevancia y viabilidad de estas políticas.

Un buen ejemplo de que es posible avanzar en el mejoramiento de las condiciones estético ambientales en la enseñanza básica y media es el Sistema Nacional de Certificación Ambiental de Establecimientos Educacionales (SNCAE), programa coordinado por la División de Educación Ambiental del Ministerio del Medio Ambiente, el Ministerio de Educación (MINEDUC), y la Organización de Naciones Unidas para la Educación, Ciencia y Cultura (UNESCO), cuyo objetivo es incentivar acciones destinadas a difundir la importancia de una cultura para la sustentabilidad y promover los valores relativos a la conservación del medio ambiente a nivel escolar. 


\section{Aproximaciones emergentes para crear nuevos espacios de aprendizaje}

En el ámbito internacional tampoco abundan las referencias sobre la calidad estética de los ambientes educativos y, cuando se encuentran, las conclusiones no suelen ser muy alentadoras ${ }^{13}$. Sin embargo, el surgimiento de algunas publicaciones durante la presente década, demuestra un creciente interés por estudiar las relaciones entre calidad del ambiente, clima y aprendizaje escolar ${ }^{14}$.

En The impact of school Environments, publicación que aborda el estado del arte en lo que al diseño de espacios y su impacto en los procesos de aprendizaje concierne, los autores inician sus observaciones con una cita del experto en tecnologías de la información y comunicación Stephen Heppell, quien advierte sobre la enorme complejidad que supone proyectar espacios eficientes desde un punto de vista pedagógico: 'Nadie sabe cómo prevenir una 'pérdida de aprendizaje' cuando [se] diseña pedagógicamente una sala, mientras que sabemos mucho sobre cómo diseñar [para evitar] una pérdida de calor" (2005: 3). Lo que se requiere, afirman los autores, es la emergencia de nuevas aproximaciones que se encuentren en coherencia con los desafíos del nuevo siglo (2005: 3). Así, se comprende también la necesidad de abrir paso a diferentes perspectivas en el aprendizaje, rechazando la imposición de modelos o la implementación de diseños estandarizados.

Los expertos concuerdan en que la naturaleza diversa de los usuarios se replica, naturalmente, en su necesidad para con el ambiente edificado; de igual manera, cabe considerar como factores de alta influencia a las variables físicas básicas (temperatura, ruido, calidad del aire) y, aunque ha sido abundantemente discutido, al color y a la luz (2005: 4-7, 36). Se subrayan, a la par, la relevancia de que el aula exhiba un grado de flexibilidad en la organización de los elementos en su interior y, por otro lado, que la propia institución educativa se halle vinculada significativamente con la comunidad a la que pertenece (2005: 7).

Lo que no es objeto de polémica para los autores, es el hecho de que el ambiente es uno más entre tantos aspectos que intervienen en el proceso de aprendizaje de los estudiantes, junto a factores de orden "pedagógico, socio-cultural, curricular, motivacional y socio-económico" (2005: 35). En este marco, se trata de un asunto extraordinariamente complejo, al que los investigadores asocian con una "cadena de eventos" en la que se engarzan las causas y los efectos que participan de la problemática educacional; una ilustración de ello, indican los autores, es que un ambiente en malas condiciones puede conllevar a la ausencia de estudiantes por enfermedad, o francamente a su alejamiento, cuestión que lesionaría el tiempo consagrado al aprendizaje; algo similar ocurre con el estado del propio edificio que sirve a la institución, pues su empeoramiento, argumentan, impregnaría en sus usuarios - docentes y estudiantes - un ánimo íntimamente relacionado con esa situación de deterioro (2005: 35). Siguiendo esta línea de argumentación, podemos postular que la precariedad estética de los espacios educativos, de sus muros, instalaciones, áreas verdes, etc., constituye un factor que puede impregnar en la comunidad una atmósfera deteriorada del ambiente. Por el contrario, aquellos espacios educativos que evidencian cualidades estéticas más consistentes pueden contribuir a generar en la comunidad un sentido de mayor pertenencia e identificación con la institución escolar. 
En otro informe reciente sobre la Infraestructura escolar y su relación con los aprendizajes en la educación básica latinoamericana (2011), los autores centran su discusión en el impacto positivo que puede generar las condiciones físicas favorables del entorno escolar en el proceso de aprendizaje de los estudiantes, considerando factores documentados como la comodidad, luz, temperatura, calidad del aire, etc. Con ese objetivo, los investigadores han tomado por referencia el Segundo Estudio Regional Comparativo y Explicativo (SERCE), llevado a cabo en 2006 en dieciséis países latinoamericanos, uno de los pocos documentos en existencia que recoge información atingente de manera global y acabada (2011: 2).

Los investigadores indican que datos arrojados por el SERCE muestran con claridad la amplia brecha existente en materia de infraestructura entre las zonas urbanas y rurales, como asimismo entre los estratos altos y bajos. Pese a que la situación dominante es aquella de la deficiencia en las condiciones de los servicios básicos y de otros aspectos relativos los espacios edificados de las escuelas de la región (2011: 5), no cabe duda que las instituciones urbanas y privadas manifiestan una "ventaja significativa" respecto de sus pares (2011: 6-14).

Por su parte, en La estética de las edificaciones escolares en Educación Infantil en la Comunidad Autónoma (Crespo y Pino, 2010), las autoras abordan analíticamente en su estudio el estado de veintitrés instituciones escolares, muchas de ellas en pobres condiciones de mantención y con instalaciones a las que las autores consideran poco amigables con los estudiantes. Reparando en ello, argumentan la necesidad que estos espacios tienen de contar con un "diseño estético rico en formas, colores, imágenes y estructuras que propicie su creatividad e imaginación, fomente la comunicación, estimule el juego y la movilidad, cree un sentimiento de bienestar, y favorezca la exploración y el descubrimiento, la construcción y la creación." (2010: 485-486).

Si bien las expertas admiten que la "configuración estética" de los recintos escolares responde, también, a normas y valores cultivados de manera particular en cada sociedad y que, por tanto, varían según cada contexto específico, ello no oblitera el nexo fundamental entre las condiciones sensibles del entorno y los procesos de aprendizaje que ahí tienen lugar (2010: 487-488). En el estudio de campo que las investigadoras realizan se recogen algunos datos de interés. Por ejemplo, el haber de ciertas constantes, como las fachadas de las escuelas con un claro acento horizontal, el uso protagónico del hormigón y la abundancia de cierres metálicos. Por otro lado, los patios, en los que nuevamente el hormigón es predominante, se caracterizan por su monotonía (2010: 491-493, 497).

En cuanto a la percepción de las docentes, es esencial rescatar que aquellas consultadas indicaron que "no están interesadas en iniciar el trabajo de la sensibilidad estética con sus alumnos", aún cuando hay objetivos curriculares expresamente definidos en ese orden (2010: 504). Como parte de sus conclusiones, las investigadores afirman que -pese a alguna excepciones- los espacios escolares no han sido diseñados para ser estéticamente significativos, asunto que de algún modo refrenda el aprendizaje reproductivo y no creador (2010: 505-506), lo que obliga a postular como necesidad la incorporación de consideraciones sobre la cuestión sensible en dichos recintos: diversidad cromática, presencia de naturaleza, ambientes amigables, etc. 


\section{La necesidad de prestar atención a la estética cotidiana del entorno escolar}

La construcción de ambientes educativos de mayor calidad estética -más allá de su valor funcional y decorativo- podría favorecer la creación de un clima de enseñanza y aprendizaje más interesante y, por ende, contribuir a mejorar la calidad de vida de la comunidad escolar. Desde esta perspectiva, visibilizar la dimensión estética del entorno escolar no sólo se justifica por su valor intrínseco, sino también por su aporte en el ámbito pedagógico, por cuanto lo que está en juego, en última instancia, es cómo la estética cotidiana "educa", afecta y/o determina la imagen que construimos y proyectamos de la institución escolar, transformándose en un referente de representación y configuración de su propia identidad ${ }^{15}$.

Los estudios relacionados con la estética cotidiana -en países como México, Inglaterra, Finlandia y Estados Unidos- son cada vez más frecuentes en diversos ámbitos disciplinares (arquitectura, diseño, publicidad, educación, salud, entre otros). Existe un interés creciente por ampliar el campo de la estética más allá de las artes y del terreno propiamente filosófico, el que tradicionalmente se ha concentrado en conceptos tales como el juicio estético, el gusto y la belleza ${ }^{16}$. Esta tendencia ha sido consignada por diversos autores, por ejemplo Arto Haapala (The Aesthetics of Everyday Life, 2005: 39) plantea que uno de los acontecimientos más recientes en estética filosófica ha sido la ampliación de su campo de estudio. No mucho tiempo atrás, el término "estética" se usaba como sinónimo de "filosofía de las artes," y aún hoy día, cuando uno lee introducciones a la estética, ve que el énfasis está puesto con tal firmeza en los problemas del arte, que otras áreas de interés estético -como la naturaleza y los objetos cotidianos- quedan casi sin ser siquiera mencionadas. Podría dársele un nuevo significado a la frase "el arte de vivir", es decir, valorar las particularidades de lo cotidiano. Ello agrega una nueva dimensión al pensamiento estético; una dimensión que, en realidad, es dominante en nuestra vida diaria. La estética no tiene que ser solamente sobre lo extraordinario; también puede ser sobre nuestras rutinas diarias.

Un ejemplo de esta tendencia son las publicaciones editadas por el International Institute of Applied Aesthetics ${ }^{17}$, que exploran el entorno cotidiano y sus implicancias medio-ambientales en relación con aspectos no artísticos de la experiencia humana y la cultura. De esta forma, en un esfuerzo por promover una estética social, se están desarrollando nuevas líneas de investigación vinculadas a las instituciones, los materiales, la comida, la contaminación y la restauración de lo sagrado, entre otros. Una aproximación al concepto "estética social" es planteada en The Aesthetic of Every Day Life. Andrew Light y Jonathan Smith, Editores. Columbia University Press (2005): Es una estética de la situación. Como todo orden estético, la estética social es contextual. Y es también altamente perceptual, ya que un intenso conocimiento por la vía de la percepción es la base misma de la estética. (p. 30). Ciertamente no existe un objeto de arte en la estética social, pero la situación misma pasa a ser el foco de la atención perceptual, como sucede en la escultura conceptual o en los ambientes.

Una de las pioneras en abordar esta línea investigativa fue la profesora Katya Mandoki, quien, en su libro Prosaica: Introducción a la estética de lo cotidiano (Grijalbo, 1994), propone una nueva manera de abordar las experiencias de nuestra vida diaria a partir de las herramientas ofrecidas por la disciplina estética. 
Tempranamente, Mandoki advierte que sus observaciones se desmarcan del proyecto de la estética occidental -esto es, de aquel pensamiento filosófico centrado en las artes- pues su objeto es, en efecto, uno extensamente marginado de los espacios académicos, a saber, la cotidianeidad como fenómeno estético.

Un asunto protagónico para Mandoki, y que hace factible abordar estéticamente lo cotidiano, es centrar la atención del análisis no en el objeto sino en el sujeto. Si la estética tradicional o "poética" ha conjugado sus esfuerzos en discutir la naturaleza de la "obra de arte", llegando a atribuirle características de orden trascendental, la "prosaica", por su parte, habrá de enfocar su discurso en torno a la experiencia estética del sujeto en relación con su entorno. A su vez, la "sensibilidad hacia lo cotidiano" implica ampliar nuestras experiencias a los diferentes registros que integran la vida diaria en términos estéticos; por consiguiente, también a lo feo y lo desagradable, que han sido relegados a los últimos planos de la discusión (1994: 29-32; 2006: 9 y ss.; 2006b: 44; 2007a: 7 ss.).

Ahora bien, en relación con el entorno escolar, el aporte más interesante de Mandoki al análisis estético de lo cotidiano es la noción de "matrices", la que podríamos perfilar como los distintos escenarios concretos -e interconectados por cierto- que configuran la sensibilidad estética de un individuo en el contexto de la familia, la escuela, la política, etc. El término "matrices estéticas" alude a la manera en que se constituyen los aspectos sensibles en instituciones, prácticas y grupos sociales, en tanto colectivos donde se configuran estrategias de enunciación, interpretación, y de vivir la experiencia cotidiana. De acuerdo a la autora, estas "matrices" actúan por superposición: "Si pintáramos algo sobre varias placas de vidrio transparente, una a una, y las juntásemos, veríamos un dibujo complejo y con cierta profundidad. Algo semejante sucede con la sensibilidad del individuo." (1994: 181). Para el estudio de estos diversos registros, Mandoki propone a la vez variables muy interesantes, como son, los aspectos relativos a la "dramática", la "retórica", la "icónica", la "léxica", la "acústica" y la "quinésica", cuestiones semánticas y simbólicas presentes en las instancias cotidianas que determinan nuestra sensibilidad. Sin duda, el aporte de la autora resulta fundamental, pues pone en un lugar de primera importancia a la dimensión estética de la experiencia educacional, como asimismo, entrega herramientas esenciales para su examen en el marco aún más amplio de la biografía estética del individuo.

En este sentido, cada institución posee ciertos rasgos estéticos propios que la constituyen como espacio de sensibilidad diferenciabley susceptible de caracterización, como es el caso de la institución escolar. Este concepto es particularmente relevante en el contexto del presente artículo, por cuanto resitúa la estética en una perspectiva social cuyo objetivo fundamental es decodificar el fenómeno de la sensibilidad en la vida cotidiana institucional.

Según Mandoki, algunos rasgos distintivos de la "matriz estética escolar" (1994: pp. 199-208) son la homogeneización de los alumnos, el riguroso uso de uniformes, la existencia de espacios y tiempos prohibidos, la puerta cerrada, una acústica que subraya el silencio, matizado por la irrupción de pequeños recreos en los cuales predomina el bullicio y la agitación como válvulas de escape, el énfasis, por una parte, en programas de estudio que resaltan ciertos aspectos de la realidad y, por otra, 
la omisión de contenidos como la historia del arte y sus códigos visuales. En pocas palabras, un modo de concebir y organizar estéticamente las nociones de espacio, tiempo y movimiento, así como también la iconografía, el léxico y la acústica, entre otras dimensiones de la cultura escolar.

Por su parte, prestigiosas universidades como Oxford y Columbia también dan muestra de un creciente interés por investigar sobre la estética cotidiana, más allá de una perspectiva meramente académica. La necesidad de considerar seriamente este ámbito como un factor que puede influir en la calidad de vida y -de un modo muy realen el estado del mundo, es el propósito fundamental de la obra Everyday Aesthetic de Yuriko Saito. Se trata de reconocer cómo "el poder de la estética" puede afectar diversos aspectos de nuestra existencia, el estado de la sociedad y del mundo. Según este autor (2007: 6), las respuestas estéticas que formulamos diariamente y que a simple vista pueden parecernos triviales, insignificantes y sin importancia, a menudo llevan a serias consecuencias morales, sociales, políticas y medioambientales.

La tesis fundamental de Saito -también muy relevante en el contexto del presente artículo- es que aquellos aspectos de nuestra vida cotidiana que parecieran triviales, comunes, inocuos, mundanos y hasta frívolos, tienen consecuencias sorprendentemente serias y concretas en los planos ambiental, moral, social, político y existencial. A modo de ejemplo, plantea como nuestra relativa omisión del ambiente laboral cotidiano puede tener implicancias negativas. Más aún, según ella, los ambientes y objetos con los que interactuamos cada día no pueden sino ejercer un impacto sustancial sobre nuestra vida. Como nos recuerda Berleant, dice Saito (2007: 52), "la forma en que nos relacionamos con los paisajes prosaicos del hogar, el trabajo, los viajes y la recreación indica de manera importante la calidad de nuestra vida." Este planteamiento podría aplicarse al contexto educacional en los siguientes términos: la forma en que nos relacionamos a nivel escolar con las personas, espacios, muros, objetos, imágenes, sonidos, texturas y olores revela de un modo significativo la calidad de nuestra vida en este ámbito y, consecuentemente, también afecta la calidad de nuestro desarrollo cognitivo.

De esta forma, al descuidar la experiencia estética (la cual está íntimamente conectada con nuestros juicios, acciones y decisiones de cada día) perdemos no sólo la oportunidad de enriquecer y desarrollar la sensibilidad, sino también el potencial para mejorar la calidad de nuestra experiencia cotidiana, personal y social. Consecuentemente, Saito -al igual que Mandoki- propone ampliar la búsqueda estética más allá de los enfoques centrados en lo artístico que han dominado el discurso occidental de la era moderna. Desde esta perspectiva, Saito postula una "estética de lo cotidiano" que haga justicia a la heterogeneidad de la vida que experimentamos día a día, incluyendo cualquier reacción que podamos tener ante las cualidades sensibles de un objeto, fenómeno o actividad (2007: 9), abarcando con ello tanto las respuestas placenteras como las de desagrado, algo que desde ya se revela como una ruptura con la disciplina estética en los términos que acostumbramos. Hacer consciente esta doble vertiente de nuestra experiencia estética -placer y desagrado- y, eventualmente, reconocer también estados de cierta apatía o indiferencia estética puede contribuir no solo a desarrollar en mayor plenitud diversas potencialidades en este ámbito, sino también a percibir de modo más lúcido las fortalezas y debilidades estéticas de las instituciones escolares. 
En oposición a la estética que promueve la idea de una actitud desinteresada o distanciada, que omite otras actitudes no limitadas a contextos excepcionales de atención, Saito defiende aquellas experiencias que resultan del cotidiano, pues cercar la experiencia estética bajo las premisas tradicionales -procediendo a discriminar a partir de lo funcional y lo no funcional- no nos permitiría valorar aquellas cosas extraordinarias ocultas en la rutina. Para esto, es necesario poner en juego una actitud de extrañamiento, vale decir, hacer extraordinario lo ordinario, estrategia que sensibilizaría nuestra percepción en contraste con la familiaridad que profesamos hacia lo cotidiano, aunque comprometa ello también una pérdida irrenunciable del valor corriente de la vida diaria. En este orden, uno de los propósitos fundamentales de una "estética de lo cotidiano" es iluminar la potencialidad estética olvidada de lo trivial o de lo mundano y, a la vez, iluminar aquellas dimensiones de nuestra vida rutinaria que normalmente no nos llevan a experiencias estéticas memorables o placenteras en su contexto regular (2007: 50-51).

Con todo, la predilección por lo trivial que una "estética de lo cotidiano" profesa no equivale a decir que sea esta una evidencia literalmente insignificante, ya que la importancia de su estudio, como ya señalamos, estriba en la influencia que la dimensión estética ejerce en nuestra vida diaria. Saito afirma que la estética posee una capacidad como mediadora social altamente competente en términos de calidad de vida, como por ejemplo lo confirman las políticas medioambientales y urbanísticas. En este sentido, según la autora, la estética fortalece su alianza histórico-epistemológica con la ética, por cuanto existe la conciencia de una responsabilidad social y ecológica indesmentible, como asimismo, cumple una función de primera importancia en el desarrollo de la afectividad o apego hacia la cosa que es objeto de juicio estético (2007: 72 y ss.). Este último asunto es cardinal, pues la adaptación y subsecuente identificación de los individuos con respecto a ciertos lugares dependería de factores estéticos orientados a enriquecer la relación entre unos y otros, argumento que, ciertamente, debería ser considerado en el contexto educativo.

\section{Conclusiones}

Chile crece sostenidamente y el aumento del presupuesto en educación durante la última década así lo evidencia; sin embargo, el modelo instrumental que se está impulsando para mejorar la calidad de la educación -focalizado principalmente en incrementar el rendimiento en lenguaje, matemáticas y ciencias- no está a la altura de la reforma educacional que la sociedad requiere en el siglo 21. En este sentido, resulta paradójico que en medio de la prosperidad financiera actual exista tan poca preocupación por la estética del entorno escolar de los establecimientos educacionales del país.

La invisibilidad del "tercer maestro" 18 no es de extrañar. Prueba de ello es que, generalmente, los discursos y prácticas referidos a la calidad de la educación omiten y/o desconocen la importancia del entorno educativo, lo cual se refleja en la ausencia de investigación y de políticas públicas que contribuyan a mejorar las condiciones físicas, materiales y estéticas del ambiente escolar.

Podrán mejorar el desempeño docente y el rendimiento de los estudiantes en algunas asignaturas, el compromiso de los apoderados y la calidad de la formación 
del profesorado en los centros de educación superior, pero si no se considera seriamente la dimensión estética del entorno escolar como un aspecto relevante de la "agenda pendiente en educación", en otras palabras, si no se visibiliza el (f)actor invisible desde una perspectiva teórica y práctica, difícilmente podremos afirmar con propiedad -en un sentido más integral- que hemos alcanzado una educación de mejor calidad.

Paradójicamente, aunque no veamos el ambiente cotidiano -o no sea fácilmente observable- el entorno es el aspecto más visible del trabajo hecho en la escuela (Gandini, 2002). A través de éste se envía el mensaje de qué han pensado los adultos acerca de la calidad y el poder de enseñanza del espacio. En efecto, el diseño del espacio físico puede acoger -o dificultar- los encuentros, la comunicación y los vínculos, así como la disposición de las estructuras, objetos y actividades puede favorecer -o dificultarla toma de decisiones, la resolución de problemas y el descubrimiento.

Es más, el entorno y sus cualidades estéticas -espacios, formas, materialidades, suelos, muros, colores, imágenes, objetos, luces, sombras, sonidos, texturas, olores, áreas verdes- jamás serán neutros. En consecuencia, cada elemento del ambiente que rodea a la niñez debe ser seleccionado cuidadosamente para enriquecer la experiencia escolar. El diseño espacial posee capacidades afectivas en tanto permite a quienes lo ocupan construir vínculos, hecho significativo en el contexto escolar (Curtis y Carter, 2003).

Asimismo, es necesario construir espacios educativos que incorporen la perspectiva del alumnado, de los docentes, apoderados y otros involucrados en el proceso de enseñanza y aprendizaje (Woolner, 2010). En este sentido, una visión más compartida y pluralista respecto a cómo podría recrearse el ambiente escolar cotidiano, no implica desperfilar el rol que deben cumplir la dirección del establecimiento y su cuerpo docente y administrativo, respecto a la toma de decisiones según corresponda en cada ámbito. Es evidente que, a la hora de diseñar, construir, remodelar o modificar el entorno, los desafíos y factores involucrados pueden ser de diversa índole, complejidad y magnitud, y no pocos de ellos ameritan decisiones compartidas y el concurso de especialistas.

Sin embargo, escuchar "la voz" de la comunidad, especialmente del alumnado y acoger algunas de sus ideas, sugerencias y/o proyectos, puede constituir no sólo un valioso ejercicio desde el punto de vista educativo, sino también una instancia enriquecedora para contribuir a establecer un "diálogo" más fluido, un mayor sentido de pertenencia e identidad, entre los estudiantes y el entorno que habitan. Esta formulación deriva de Thomson (2008): los niños no deben ser simplemente considerados como seres en proceso de maduración, sino como personas capaces de emitir opiniones fundadas y presentar puntos de vista personales. Dentro de este contexto se emplea el concepto de permitir la expresión de la "voz" de cada alumno, considerando las características particulares de cada uno a través de la producción de imágenes.

Cañizares (2008) también plantea que la interacción con el entorno es fundamental al considerar el diseño de un edificio destinado a la educación. Desde esta perspectiva, incorporar a su arquitectura rasgos propios de la cultura local puede facilitar la creación de un sentido de pertenencia a la comunidad educativa. 
No faltarán aquellos que se resistan a cualquier alteración del entorno escolar bajo diversos argumentos y/o excusas: carencia de recursos económicos, respeto a la tradición institucional, amenazas al proceso educativo, al concepto de autoridad, otras. Al respecto, cabe señalar que las intervenciones más costosas no son, necesariamente, las más exitosas. Y a menudo, las más económicas suelen ser mejor recibidas por la comunidad, ya que no alteran estructuralmente los espacios. (Woolner, 2010). Por otra parte, también hay que tener presente que el ambiente de aprendizaje debe ser dinámico; por ejemplo, ofrecer materiales y oportunidades para lo que Howard Gardner llama "inteligencias múltiples". (Curtis y Carter, 2003). De un modo similar, integrar objetos que generen un elemento de cierto misterio y asombro también puede contribuir a enriquecer el entorno educativo, especialmente en los niveles de enseñanza básica.

Las siguientes preguntas pueden contribuir a explicitar y/o explorar la "matriz estética cotidiana" de los espacios educativos, la "voz de la comunidad", para dilucidar en términos más concretos algunos de estos planteamientos a nivel escolar:

1. ¿Qué factores estéticos (lugares, espacios, áreas verdes, imágenes, objetos, colores, sonidos, olores, otros) contribuyen a enriquecer la experiencia escolar cotidiana? ¿Cuáles la empobrecen?

2. ¿Existen áreas verdes (árboles, prados, jardines, plantas, huertos, invernaderos, etc.)? ¿En qué estado se encuentran, qué evidencian, qué "enseñan" implícitamente: invitan a cuidar o incentivan el descuido del medio ambiente?

3. ¿Cómo es la iluminación -natural, artificial, mixta-, es adecuada a las necesidades de los distintos espacios educativos?

4. ¿Qué usos -o abusos- de imágenes, grafismos evidencian los muros del establecimiento escolar (pasillos, salas de clase, patios, etc.) en los distintos niveles de enseñanza?

5. ¿Con qué criterios se determina el color de los muros, y contribuye a crear una atmósfera adecuada en cada espacio educativo?

6. ¿En qué medida los espacios de enseñanza y aprendizaje son flexibles, pueden ser adaptados, según propósitos específicos, a las necesidades de aprendizaje de los propios estudiantes?

7. ¿Cómo es el entorno sonoro de la escuela? ¿Cuáles son los espacios con ruidos, música y/o silencio? ¿Cómo se relacionan estos sonidos con las experiencias pedagógicas que se desarrollan en su entorno?

8. ¿Existen ambientes de aprendizaje que incluyan imágenes relativas al patrimonio artístico/cultural, elementos naturales, distintas materialidades, objetos mecánicos, electrónicos, juegos, u otros? ¿Qué trabajo pedagógico se hace en ellos?

9. ¿Cómo es el entorno de olores en la escuela? ¿Cuáles son los espacios con y sin olores (naturales, químicos, mal olor, etc)? ¿Cómo se relacionan estos olores con las experiencias pedagógicas que se desarrollan en su entorno?

10. ¿Qué nociones de orden, limpieza e higiene se promueven y/o evidencian en distintos ámbitos del espacio escolar?

11. ¿Cómo se usan -o abusan- las diversas fuentes de energía (electricidad, agua, combustibles, otras), en qué medida se cuidan o despilfarran, se ahorran o reciclan? ¿Qué otros sistemas de reciclaje existen en el entorno escolar? 
12. ¿Quiénes determinan cómo distribuir, organizar, decorar y remodelar los distintos espacios escolares?

13. ¿En qué medida los estudiantes y los profesores se identifican y/o valoran positivamente la estética del entorno escolar?

14. ¿Qué proyectos, medidas, acciones, procedimientos de evaluación podrían contribuir a mejorar la calidad estética del entorno escolar como objetivo permanente del proyecto educativo?

\section{Referencias}

Arredondo, Inés (2007). La Calidad de la Educación: Ejes para su definición y evaluación, Organización de Estados Iberoamericanos, OEI, Programas - Calidad y Equidad.

Boys, Jos (2011). Towards Creative Learning Spaces. London: Routledge.

Brunner, José Joaquín (2006). Concepto de calidad en Educación, Santiago: Fundación Chile.

Cañizares, Ana (2008). Kindergartens. Schools and playgrounds. Barcelona: Loft Publications.

Cornejo, Rodrigo y Redondo, Jesús María (2007). Variables y factores asociados al aprendizaje escolar. Una discusión desde la investigación actual. Estudios Pedagógicos XXXIII, $\mathrm{N}^{\circ}$ 2: 155-75, Valdivia, Chile.

Crespo, Julia María y Pino, Margarita (2010). La estética de las edificaciones escolares en educación infantil en la Comunidad Autónoma de Galicia. Revista de Educación, 351. Enero-Abril 2010. Pp. 485-511.

Curtis, Deb y Carter Margie (2003). Designs for Living and Learning. Transforming Early Childhood Environments. Redleaf Press, United.

Díaz, Eloísa (1902), Higiene escolar. Centro de Investigaciones Diego Barros Arana, Dirección de Bibliotecas, Archivos y Museos, Santiago, Chile.

Duarte, Jesús, Gargiulo, Carlos y Moreno, Martín (2011). Infraestructura Escolar y Aprendizajes en la Educación Básica Latinoamericana: Un análisis a partir del SERCE. Banco Interamericano de Desarrollo, División de Educación, (SCL/ EDU), NOTAS TÉCNICAS, \# IDB-TN-277.

Edwards, Verónica (1991). El Concepto de Calidad de la Educación. Oficina Regional de Educación para América Latina y el Caribe. (OREALC), Unesco, Santiago, Chile.

Egaña, María Loreto (2000). La educación primaria popular en el siglo XIX en Chile: Una práctica de política estatal. Editorial Lom, Santiago, Chile.

Eisner, Elliot (2005). Reimagining Schools. London, Routledge.

Errázuriz, Luis Hernán (1993). Historia de un Área Marginal. La Enseñanza Artística en Chile, 1797 - 1993, Ediciones Universidad Católica de Chile.

Errázuriz, Luis Hernán (2002). Cómo Evaluar el Arte. Ministerio de Educación de Chile. Fontaine Editores.

Errázuriz, Luis Hernán (2006). Sensibilidad Estética: Un Desafio Pendiente en la Educación Chilena. Instituto de Estética Pontificia Universidad Católica de Chile. Santiago: Frasis Editores. 
Gandini, Lella (2002). The Story and Foundations of the Reggio Emilia Approach. En: Teaching and Learning. Collaborative Exploration of the Reggio Emilia Approach. Upper Saddle River, N.J.: Merrill Prentice Hall.

Higgins, Stephen, et al. (2005). The Impact of School Environments: A literature review. Newcastle upon Tyne: The Centre for Learning and Teaching, School of Education, Communication and Language Science, University of Newcastle.

Larraín, Verónica y Hernández, Fernando (2003). Visual Central Marks of Identity in Children's as an Example of Emergent Changes in Childhood. Centre for the Study of Changes in Culture and Education (CECADE) Scientific Park of Barcelona.

Light Andrew y Smith Jonathan (2005). The Aesthetic of Every Day Life. Columbia University Press.

Mandoki, Katia (1994). Prosaica, Introducción a la Estética de lo Cotidiano, Editorial Grijalbo, México.

Mandoki, Katia (2006a). Estética cotidiana y juegos de la cultura: Prosaica I. México, D.F.: Siglo XXI.

Mandoki, Katia (2006b). Prácticas estéticas e identidades sociales: Prosaica II. México, D.F.: Siglo XXI.

Porcher, Louis (1975). La Educación Estética: Lujo o Necesidad, Buenos Aires: Editorial Kapelusz.

Saito, Yuriko (2007). Everyday Aesthetic. Oxford University Press.

Salas, Marchan (1913). La Educación Estética en la Enseñanza Secundaria, en: Congreso Nacional de Enseñanza Secundaria. Tomo II, Memorias, Actas. Santiago, Chile.

Shallcross, Tony y Robinson, John (2006). Creating Sustainable Environments in our Schools. Paul Pace. Arjen Wals. Trenthham Books Limited, USA.

The Third Teacher: 79 Ways You Can Use Design to Transform Teaching \& Learning (2010). A Collaborative Project: OWP/P Architecs + Furniture + Bruce Mau Design. Abrams, New York.

Von Bonsdorff, Pauline y Haapala, Arto (1999). Aesthetic and human environment. International Institute of Applied Aesthetic Series vol. 6 Finland.

Woolner, Pamela (2010). The Design of Learning Spaces. Continuum International Publishing Group, London.

\section{Notas}

1. El presente artículo forma parte del marco teórico de la investigación Fondecyt (Fondo Nacional de Investigación Científica y Tecnológica), No 1120058, (20122013). Colaboró como asistente de investigación el Sr. Daniel González Erices. Producto de dicha investigación, próximamente será publicado "Cultura visual escolar: Investigación de los muros de primero básico", en la Revista Estudios Pedagógicos de la Universidad Austral de Chile.

2. Debate de alto nivel de la ONU sobre educación de calidad, en: Internacional de la Educación, junio 2013. http://www.ei-ie.org/spa/news/news_details/2589

3. Véase: "Presupuesto para Educación 2013: Fuerte Aumento en Áreas Clave". Temas Públicos $\mathrm{N}^{\circ}$ 1083, 12 de octubre de 2012. www.lyd.org 
4. Véase: "Indicadores de calidad de la Educación Básica y Media en Chile.” Biblioteca del Congreso Nacional de Chile. Departamento de Estudios, Año XV, No 306, Enero 2005; Brunner José Joaquín (2006); Arredondo Inés (2007).

5. Véase: Calidad de la educación: Institucionalidad para el cambio. Análisis del Proyecto de Ley de Aseguramiento de la Calidad de la Educación Parvularia, Básica y Media. Boletín 5083-04. Abril, 2010 No $^{\circ}$. Documento elaborado a partir de un taller de discusión en el que participaron Jorge Manzi, Sergio Martinic, Lorena Meckes, Francisco Lagos. Edición general: Ignacio Irarrázaval, M. Ángeles Morandé.

6. Eisner, Premio Nacional de Educación (EEUU) y Profesor Emérito de la Universidad de Stanford, es uno de los pensadores que más ha investigado y publicado sobre el sentido y los propósitos de la educación, considerando la dimensión estética y el rol que juegan las artes desde una perspectiva cognitiva. Véanse por ejemplo: The Educational Imagination (1979); Educar la Visión Artística (1995); The Kind of Schools We Need (1998); El Arte y la Creación de la Mente (2002); Reimagining Schools (2005).

7. Sigla para Sistema Nacional de Medición de la Calidad de la Educación.

8. Sigla para Prueba de Selección Universitaria.

9. Anónimo. (2 de junio de 2010). Prueba Simce 2010. El mostrador, s/p.

10. Sigla para Organización para la Cooperación y el Desarrollo Económico.

11. Véase: Artists in Schools", A handbook for teachers and artists. Caroline Sharp, Karen Dust.(1997). National Foundation for Educational Research, Calouste Gulbenkian Foundation.

12. La búsqueda bibliográfica sobre el tema no dio resultados. Tal fue el caso de la indagación realizada por el autor del presente artículo en diversas bases de datos; entre ellas, la de la Biblioteca de la Facultad de Educación de la Pontificia Universidad Católica de Chile.

13. Véase: Julia María Crespo y Margarita Pino (2010).

14. Véase: Alison, Transforming Children's Spaces (2010). The Third Teacher, 79 Ways you can use design to transform teaching \& learning. A Collaborative Project (2010). Boys, Towards Creative Learning Spaces (2011). Ehmann, Borges, Klanten, Learn for life. New architecture for new learning (2012).

15. El universo visual como representación y configuración de la identidad es abordado por Verónica Larraín y Fernando Hernández (2003).

16. Véase: Aesthetic. Key Concepts in Philosophy. Daniel Herwitz. Continuum International Publishing Group (2008).

17. Una publicación directamente relacionada con el tema de esta investigación es: Aesthetic in the Human Environment. Edited by Pauline von Bonsdorff and Arto Haapala (1999).

18. Este concepto surge -después de la Segunda Guerra Mundial- en la pequeña ciudad italiana de Reggio Emilia, gracias a la propuesta pedagógica impulsada por el educador y filósofo Loris Malaguzzi (1924 - 1994). Según esta filosofía, junto a los docentes y apoderados, el entorno es el tercer maestro. Por lo mismo, las experiencias en este juegan un papel fundamental. Todos los sentidos participan de la educación de los niños(as) quienes disfrutan de cada una de estas experiencias mientras aprenden casi sin darse cuenta. Los materiales utilizados son mayormente elementos de la naturaleza como por ejemplo, conchas marinas, estrellas de mar, plumas, la luz, el agua entre otros. 